\title{
Transcriptomic response of the Antarctic pteropod Limacina helicina antarctica to ocean acidification
}

\author{
Kevin M. Johnson ${ }^{1,2}$ and Gretchen E. Hofmann ${ }^{1 *}$
}

\begin{abstract}
Background: Ocean acidification (OA), a change in ocean chemistry due to the absorption of atmospheric $\mathrm{CO}_{2}$ into surface oceans, challenges biogenic calcification in many marine organisms. Ocean acidification is expected to rapidly progress in polar seas, with regions of the Southern Ocean expected to experience severe OA within decades. Biologically, the consequences of OA challenge calcification processes and impose an energetic cost.

Results: In order to better characterize the response of a polar calcifier to conditions of OA, we assessed differential gene expression in the Antarctic pteropod, Limacina helicina antarctica. Experimental levels of $p \mathrm{CO}_{2}$ were chosen to create both contemporary $\mathrm{pH}$ conditions, and to mimic future $\mathrm{pH}$ expected in $\mathrm{OA}$ scenarios. Significant changes in the transcriptome were observed when juvenile L. h. antarctica were acclimated for 21 days to low-pH (7.71), mid-pH (7.9) or high-pH (8.13) conditions. Differential gene expression analysis of individuals maintained in the low-pH treatment identified down-regulation of genes involved in cytoskeletal structure, lipid transport, and metabolism. High pH exposure led to increased expression and enrichment for genes involved in shell formation, calcium ion binding, and DNA binding. Significant differential gene expression was observed in four major cellular and physiological processes: shell formation, the cellular stress response, metabolism, and neural function. Across these functional groups, exposure to conditions that mimic ocean acidification led to rapid suppression of gene expression.

Conclusions: Results of this study demonstrated that the transcriptome of the juvenile pteropod, L. h. antarctica, was dynamic and changed in response to different levels of $p \mathrm{CO}_{2}$. In a global change context, exposure of $L$. $h$. antarctica to the low $\mathrm{pH}$, high $\mathrm{pCO}_{2} \mathrm{OA}$ conditions resulted in a suppression of transcripts for genes involved in key physiological processes: calcification, metabolism, and the cellular stress response. The transcriptomic response at both acute and longer-term acclimation time frames indicated that contemporary L. h. antarctica may not have the physiological plasticity necessary for adaptation to OA conditions expected in future decades. Lastly, the differential gene expression results further support the role of shelled pteropods such as $L$. $h$. antarctica as sentinel organisms for the impacts of ocean acidification.
\end{abstract}

Keywords: Limacina helicina antarctica, Pteropod, Ocean acidification, Ross Sea, pH, Southern Ocean, RNAseq, Gene expression

\footnotetext{
* Correspondence: gretchen.hofmann@lifesci.ucsb.edu

${ }^{1}$ Department of Ecology, Evolution and Marine Biology, University of

California, Santa Barbara, Santa Barbara, CA 93106-9620, USA

Full list of author information is available at the end of the article
} 


\section{Background}

Comparative transcriptomics has proven to be a powerful tool for examining organism-environment interactions in non-model species [1]. This approach has been applied in both laboratory and field settings, and has become a common method with which to assess physiological responses in marine taxa [2-5]. The advantages of comparative transcriptomics are particularly valuable in marine systems, where differential gene expression analysis has been used to explore how organisms respond to their abiotic environment. Examples include studies on adaptations to thermal stress [2, 3], population-level variation in tolerance $[4,5]$, and increasingly, studies conducted in a global change context $[1,6,7]$. In this study, we use the analysis of differential gene expression to examine the resistance of a key member of the zooplankton in the Southern Ocean, the shelled pteropod Limacina helicina antarctica, to the impacts of an advancing anthropogenic stress, ocean acidification.

Polar seas, such as the Southern Ocean, are predicted to be 'first in time' to experience the impacts of ocean acidification, the reduction of $\mathrm{pH}$ and saturation states for minerals such as aragonite as a result of the absorption of $\mathrm{CO}_{2}$ into surface waters [8-10]. Future acidification will be layered onto patterns of natural, present-day $\mathrm{pH}$ variability, with the cold waters of polar seas tending to hold and absorb more $\mathrm{CO}_{2}$ [11]. Thus, in polar waters, future anthropogenic ocean acidification will change carbonate chemistry sooner in time than in temperate waters. In the Southern Ocean, recent studies into variability in present-day $\mathrm{pH}$ in nearshore Antarctic regions have observed seasonal variability in $\mathrm{pH}$ dynamics [12]. Here, in winter, low-pH conditions (due to high $\mathrm{CO}_{2}$ levels) create seawater that is under-saturated with respect to aragonite, the form of calcium carbonate that makes up shells $L$. $h$. antarctica. In summer, a significant alkalization event has been observed [12], likely the result of photosynthesis and $\mathrm{CO}_{2}$ draw-down driven by summer phytoplankton blooms. In addition to this seasonal variability, regions of the Southern Ocean are predicted to experience ocean acidification, and hence aragonite under-saturation conditions in the winter as early as the year 2018 [8, 9, 12]. As ocean acidification progresses, models predict rapid changes in the next 10-20 years for many regions of the Southern Ocean with significant aragonite undersaturation on an annual basis for as much as 6 months of the year by the year $2050[9,12]$. Overall, this rapid rate of change for the Southern Ocean will present a physiological and energetic challenge to calcifying marine organisms such as the shelled pteropods.

Our study organism, the pteropod Limacina helicina antarctica (Phipps, 1774), is an ideal organism to assess organismal response to future ocean acidification in Antarctic waters. L. $h$. antarctica is a holoplanktonic mollusk, and a dominant member of the macrozooplankton assemblages in the Southern Ocean [13-15]. The thin calcium carbonate shells of Limacina, and pteropods in general, are particularly vulnerable to dissolution in the under-saturated conditions that are created in low $\mathrm{pH}$ seawater $[16,17]$. Thus, pteropods are proposed as sentinel species for the impacts of ocean acidification [18] due to their aragonitic shell, a comparatively soluble for of calcium carbonate, which renders them more susceptible to dissolution in nature in under-saturated seawater $[10,13,19]$. Notably, recent assessments using scanning electron microscopy (SEM) of shell condition of Limacina spp. from both the Eastern Pacific and Southern Ocean shows that contemporary patterns of undersaturation are already causing shell dissolution [13, 14, 16]. With regard to $L$. $h$. antarctica, several investigators have noted that dissolution of the shell surface was detected in the majority of recently collected samples $[14,16]$. Although researchers have made shipboard collections and analyzed preserved shells of Limacina from the Antarctic, few studies have examined the physiological consequences of maintaining net calcification in undersaturated conditions [20,21].

Comparative transcriptomics is an ideal approach to examine the physiological underpinnings of the response of pteropods to dissolution stress $[22,23]$. In this study, we present a comparison of transcriptomes from $L . h$. antarctica that were maintained in a short-term experiment at three environmentally-relevant $\mathrm{pH}$ treatments: (i) present-day summer ( $\mathrm{pH} 8.13)$, (ii) present-day winter $(\mathrm{pH}$ 8.01), and (iii) future winter $(\mathrm{pH}$ 7.71) [12]. These experimental conditions allowed us to examine the seasonal effects of annual alkalization events, and the predicted effects of ocean acidification conditions on the transcriptome of $L . h$. antarctica. Analysis of the data revealed that $L$. $h$. antarctica responds to $p \mathrm{CO}_{2}$ changes with rapid alterations of the transcriptome that impacted the expression of genes involved in several relevant physiological processes.

\section{Methods}

\section{Field collection of animals}

Juvenile pteropods (Limacina helicina antarctica) were collected through the sea ice in McMurdo Sound in the southern Ross Sea on October $12^{\text {th }}, 2015$. Pteropod collections were performed at a depth of $50 \mathrm{~m}$ using a fixedframe bongo net $(50 \mathrm{~cm} \times 150 \mathrm{~cm}$ net with $333 \mu \mathrm{m}$ mesh; cod ends with $200 \mu \mathrm{m}$ and $333 \mu \mathrm{m}$ mesh) deployed through a dive hole drilled in the sea ice at a near-shore site on the sea ice $\left(77^{\circ} 50^{\prime} 53^{\prime \prime} \mathrm{S}, 166^{\circ} 35^{\prime} 59^{\prime \prime} \mathrm{E}\right)$. The bongo net was equipped with 2 small floats attached at the cod end to prevent the ends from pinching in low current. In 
addition, a swiveling double shackle was used to attach the rotating towing yoke on the bongo net to the end of the winch line. This allowed the net to rotate into a horizontal position in the water column and maintain proper orientation with the currents during the deployment period. Bongo depth was estimated using a meter wheel to deploy $50 \mathrm{~m}$ of line.

\section{Post-collection handling}

After collection, pteropods from a single tow were maintained in ambient seawater $\left(-1.2^{\circ} \mathrm{C}\right)$ in a $19-1$ collection container, and quickly transported to the Crary laboratory facilities at McMurdo Station, the U.S. research station on Ross Island. Individuals used in the experimental run were maintained in seawater tables at $-1.2{ }^{\circ} \mathrm{C}$ for $48 \mathrm{~h}$ prior to being added to the pre-equilibrated $\mathrm{CO}_{2}$ exposure zooplankton culturing system.

\section{$\mathrm{CO}_{2}$ exposure experiment}

For the $\mathrm{CO}_{2}$ exposure experiment, pteropods were held in a flow-through culturing system designed to have controlled levels of $p \mathrm{CO}_{2}$ with sufficient flow to maintain macrozooplankton in long-term experiments. The system is based upon the generation of reservoir seawater sources that are connected to replicate culture tanks for each treatment. The reservoir mixing system that generated the target experimental $p \mathrm{CO}_{2}$ levels was fabricated following previously published methods [24]. Briefly, filtered, $\mathrm{CO}_{2}$-scrubbed, dry air was mixed with pure $\mathrm{CO}_{2}$ using a SmartTrak ${ }^{\ominus} 100$ Series Mass Flow Controller and a MicroTrak ${ }^{\mathrm{TM}} 101$ Series Mass Flow Controller (Sierra Instruments, USA), respectively. These reservoirs were held in a 1240-1 sea table that kept the treated seawater at the desired experimental temperature $\left(-1.2{ }^{\circ} \mathrm{C}\right)$. The $p \mathrm{CO}_{2}$ treated seawater was then pumped into the zooplankton flow-through culturing system.

The zooplankton culture system, henceforth referred to as the Z-system, consisted of 18 culture vessels that were submerged in ambient seawater surrounding the reservoir tanks. Each zooplankton culture vessel was a clear 1-1 polycarbonate plastic tank and lid (AHLT3, Aquatic Ecosystems, USA) originally designed for rearing juvenile zebrafish. Each tank contained a pair of $400 \mu \mathrm{m}$ mesh baffles (AHLB400, Aquatic Ecosystems, USA) to prevent pteropods from escaping. To ensure that the animals were exposed to a continuous flow of $p \mathrm{CO}_{2}$ treated seawater, water input was regulated at a flow rate of $2.0 \mathrm{l}$ per hour.
The volume of the 1-l tanks was replaced every $30 \mathrm{~min}$. As a result, the $p \mathrm{CO}_{2}$ levels in the culture vessels were highly similar within a treatment, and closely tracked the reservoir $p \mathrm{CO}_{2}$ concentrations.

The experimental $p \mathrm{CO}_{2}$ treatments were designed to create two conditions: (1) $\mathrm{pH}$ ranges that bracketed contemporary annual $\mathrm{pH}$ variability, and (2) $\mathrm{pH}$ conditions expected to occur under scenarios of ocean acidification for the Southern Ocean. Here, treatment conditions for contemporary $\mathrm{pH}$ were based on observations of oceanic $\mathrm{pH}$ in McMurdo Sound during the 2013-2014 summer [12]. These selected $\mathrm{pH}$ values, representing a range of current and predicted ranges of $\mathrm{pCO}_{2}$ levels, $\mathrm{pH}$, and aragonite saturation states are summarized in Table 1. Pteropods were not fed during the course of this experiment as the winter-to-summer transition in the McMurdo Sound is characterized by limited phytoplankton abundance [25].

\section{Carbonate chemistry}

Seawater chemistry for the Z-system was measured for each experimental tank on a daily basis. Temperature was measured using a wire thermocouple (HH81A, Omega), and salinity was measured using a conductivity meter (YSI 3100, USA). Z-system pH was calculated for each tank from a $20 \mathrm{ml}$ sample measured using a spectrophotometer (Bio Spec-1601; Shimadzu) and the indicator dye $\mathrm{m}$-cresol following the standard operating procedure (SOP) 6b [26]. Seawater samples (in $500 \mathrm{ml}$ borosilicate bottles) were collected directly from the reservoir vessels every 3 days; in preparation for measuring total alkalinity $\left(\mathrm{T}_{\mathrm{A}}\right)$, the bottle sample was immediately poisoned with $0.02 \%$ mercuric chloride, and stored at $+4{ }^{\circ} \mathrm{C}$ until analyzed. $\mathrm{T}_{\mathrm{A}}$ from these preserved samples was measured using an open-cell titration method with a Mettler-Toledo T50 titrator (Mettler Toledo, USA) using a $0.1 \mathrm{~mol} \mathrm{l}^{-1} \mathrm{HCl}$ in seawater titrant (Dickson Laboratory, Scripps Institute, USA). Measurements of $\mathrm{T}_{\mathrm{A}}$ were verified with a certified reference material (CRM) seawater standard [27]. From these measurements carbonate chemistry parameters were calculated using the software $\mathrm{CO}_{2}$ calc [28].

\section{Sample collection and processing}

During the experiment, pteropods were collected at the 5 time points: Time zero $\left(\mathrm{T}_{0}\right.$, collected immediately preceding the addition of animals to the Z-system), and

Table $1 \mathrm{pCO}_{2}$ treatment conditions

\begin{tabular}{|c|c|c|c|c|}
\hline Scenario & Temperature $\left({ }^{\circ} \mathrm{C}\right)$ & $\mathrm{pCO}_{2}$ ( $\left.\mu \mathrm{atm}\right)$ & $\mathrm{pH}$ & $\Omega$ aragonite \\
\hline Present-Day Summer & $-0.98 \pm .06$ & $318 \pm 46$ & $8.13 \pm .05$ & $1.67 \pm .14$ \\
\hline Present-Day Winter/ Future Summer & $-0.98 \pm .07$ & $432 \pm 44$ & $8.01 \pm .03$ & $1.30 \pm .09$ \\
\hline Future Winter & $-0.98 \pm .07$ & $902 \pm 49$ & $7.71 \pm .02$ & $0.68 \pm .03$ \\
\hline
\end{tabular}


then at 4 intervals after the start of the experiment on days $1,7,14$, and 21 . In addition to these sampling timepoints, mortality checks were conducted daily.

\section{RNA extraction and sequencing}

When collecting from the animals from the Z-system tanks, 10 actively swimming pteropods were quickly placed into a single $1.5 \mathrm{ml}$ micro-centrifuge cryovial, excess seawater was removed, and the sample was then flash frozen in liquid nitrogen. Sample vials were subsequently stored at $-80{ }^{\circ} \mathrm{C}$ until RNA extraction. Due to the small size of juvenile $L$. $h$. antarctica, RNA was extracted from pools of 10 pteropods with 1 pool for each of the replicate treatment tanks $(n=3)$. This sampling scheme provided 3 biological replicate pools for each treatment.

Total RNA extractions were performed using $500 \mu \mathrm{l}$ of $\mathrm{Trizol}^{\circ}$ reagent according to the manufacturer's instructions (Invitrogen). Each sample of total RNA was analyzed for quantity and purity using the NanoDrop ${ }^{\circ}$ ND100. RNA integrity was assessed by electrophoresis using the TapeStation 2200 system (Agilent Technologies) to calculate RNA integrity (RINe) scores. Only samples with RINe scores above 8.5 were used for library preparation in order to avoid sequencing degraded RNA products. Here, RINe scores are similar to the Bioanalzyer RIN score. Both metrics are an assessment of RNA degradation calculated by running the sample on a mini-capillary gel, and measuring the concentration of degraded RNA in relation to the intensity of the $18 \mathrm{~S}$ ribosomal peak [29].

Separate libraries $(n=39)$ were generated from highquality RNA using the Illumina TruSeq Stranded mRNA HT Sample Preparation Kit. Briefly, $2 \mu \mathrm{g}$ total RNA was added to Illumina RNA Purification beads to isolate mRNA from the total RNA. Purified mRNA was then enzymatically fragmented into 300 base-pair (bp) fragments and reverse transcribed into cDNA. Second strand cDNA synthesis utilized the dUTP method, which creates a strand-specific cDNA library [30]. Following second strand synthesis, cDNA fragments were size selected using AmpureXP ${ }^{\circ}$ beads (Beckman Coulter), and the library was amplified with 12 cycles of PCR according to the manufacturer's instructions. Completed libraries were checked for mean lengths of 428 bp (300 bp insert +128 bp sequencing adapters) using the Agilent TapeStation. Concentrations of each final library was quantified using a Qubit $^{\circ} 3.0$ flourometer (Life Technologies). All libraries were sequenced in two pools, each on two HiSeq4000 lanes. Sequencing was performed at the UC Davis Genome Center on an Illumina HiSeq4000 sequencer using paired-end 100 base-pair sequences. Outputs for each lane were treated independently throughout the quality control steps after which technical replicate samples were merged.

\section{Mapping and identification of differentially expressed genes} Raw reads from each sample were processed using Trimmomatic to remove sequencing adapters and bases with a PHRED33 score $<20$ [27]. Only trimmed sequences that were $\geq 75$ bp were included in downstream analysis. Trimmed reads of each sample were used to improve the previously published de novo transcriptome [31]. Briefly, trimmed sequence reads were assembled into a de novo transcriptome using the assembler Trinity (v2.3.2). The assembled contigs were then annotated using the NCBI software blast + (version 2.3.0) to execute a blast-x search (e-value $\leq 1 \mathrm{e}^{-5}$ ) against the previously published $L$. h. antarctica transcriptome [31], the NCBI non-redundant protein database and the reference genome for Aplysia californica (NCBI assembly GCF_000002075.1). Trimmed reads were mapped to the de novo transcriptome using RSEM with default parameters [32]. Read counts from each lane were merged for each sample immediately prior to the analysis of differential expression. Differential expression of transcripts was evaluated using a negative binomial general linearized model (GLM) as integrated in the Bioconductor $\mathrm{R}$ package edgeR-robust [33]. Within edgeR, we defined up-regulated transcripts as having a $\log _{10}$ fold change $\geq 1$, and down-regulated transcripts as having a $\log _{10}$ fold change $\leq-1$ with a false discovery rate $(F D R) \leq 0.05$ [34]. Differential expression was further assessed using three major comparisons: (i) using days 1 and 7 , short-term, acute responses to seasonally relevant changes in $p \mathrm{CO}_{2}$, (ii) acute responses to ocean acidification again using data from day 1 and day 7 , and (iii) the longer-term, acclimatory response to ocean acidification conditions using samples from days 14 and 21 (Fig. 1). From these comparisons, gene ontology enrichment analysis was performed using the Fisher's exact test $(\mathrm{FDR} \leq 0.05)$ implemented in the Blast2GO software (version 2.6.0) [35].

Finally, we examined expression profiles for sets of genes involved in four physiological and cellular processes: (i) genes involved in shell formation, (ii) genes associated with the cellular stress response, (iii) genes associated with metabolism, and (iv) genes associated with neural function. Gene identifiers for shell formation, metabolism and the cellular stress response were collected from the published Pacific oyster (Crassostrea gigas) genome [36]. Gene identifiers for neural function were retrieved from the published Limacina inflanta transcriptome, and hits for all physiological groups were blasted against the $L$. $h$. antarctica master transcriptome. Expression levels were calculated with RSEM and expressed as fragments per kilobase of transcript per million mapped reads (FPKM). FPKM values were then used to generate expression profile heatmaps for each process at both acute and acclimatory response times. Genes with similar Z-scores for each treatment across 


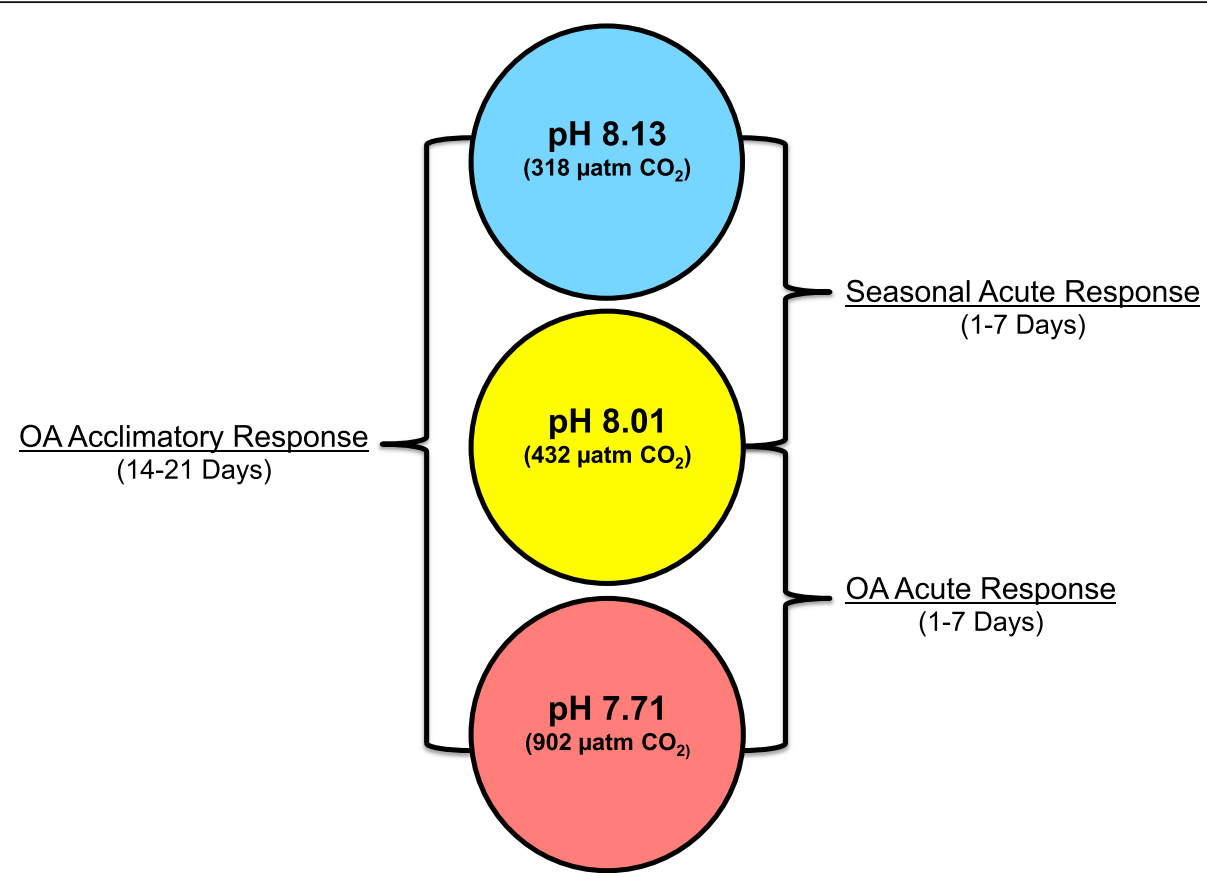

Fig. 1 Gene Expression Comparisons. Gene expression comparisons were designed to assess acute and acclimatory responses to 3 scenarios: (i) Seasonal acute response, (ii) Seasonal acclimatory response, and (iii) a future ocean acidification response

sampling days were further assessed for enrichment against the annotated transcriptome using the Fisher's exact test $(\mathrm{FDR}>0.05)$.

\section{Results}

\section{Experimental $\mathrm{pCO}_{2}$ exposures}

During the $p \mathrm{CO}_{2}$ exposure experiment, treatment conditions throughout the 21-day period were stable (Table 1). In addition, mortality in the experiment as a whole was low with fewer than 20 mortalities for any single tank across the 21-day experiment (data not shown). Throughout the exposure period, actively swimming individuals were consistently present and only these individuals were sampled for analysis.

\section{Transcriptome assembly and annotation}

Sequencing of the 39 libraries was completed on 2 lanes of an Illumina HiSeq4000 yielding a total of 803 million reads $(\sim 20.6+/-4.1$ million reads per library, range: 15.4-24.7 million reads per library). Quality and adapter trimming removed approximately $3 \%$ of the reads. All remaining high-quality reads from each of the 39 libraries were used to generate a de novo transcriptome using Trinity (v.2.3.2). Trinity produced a total of 403,210 contigs; RSEM was implemented to map sequence reads to the de novo transcriptome, which resulted in an average of $71 \%$ of sequences being successfully mapped (mapping range: $67.5 \%$ - 73.8\%). The Trinity contigs were subsequently filtered to only include sequences that were longer then $200 \mathrm{bp}$ and had at least 1 count per million in 9 of the 39 samples. This filtering resulted in 83,211 expressed contigs with $\sim 13.4+/-3.0$ million reads per sample (range: 9.4-23.0 million reads per library). A total of 37,517 (45.1\%) of these expressed contigs were successfully annotated using a Blastx search against the previously published $L$. $h$. antarctica transcriptome, the NCBI non-redundant database, and the Swissprot database. Annotations were combined with sequence reads, gene ontologies, and KEGG pathway identifiers using the Blast2GO software (version 2.6.0) [35]. Additional transcriptome assembly statistics are available in Additional file 1.

\section{Analysis of differential gene expression}

Differential gene expression was assessed for multiple comparisons using the time when the pteropods were sampled from the Z-system tanks, and in terms of what $\mathrm{pH}$ treatments were compared. The results are described below and summarized in Table 2. In addition, transcripts named in the differential expression analysis, and in the analysis for enrichment, are listed in Additional files 2, 3, 4 and 5.

\section{Pair-wise gene expression analysis}

DE following acute exposure to $\mathrm{pH}$ treatments Here we report changes in the transcriptome after exposure to $\mathrm{pH}$ conditions for 1 day (d1) and again after 7 days 
Table 2 Pair-wise differential expression results

\begin{tabular}{llll}
\hline pH comparisons & Day & $\begin{array}{l}\text { Up-regulated } \\
\text { transcripts }\end{array}$ & $\begin{array}{l}\text { Down-regulated } \\
\text { transcripts }\end{array}$ \\
\hline 8.13 vs 8.01 & 1 & 168 & 95 \\
7.71 vs 8.01 & 7 & 624 & 1554 \\
7.71 vs. 8.13 & 1 & 247 & 1818 \\
& 7 & 22 & 18 \\
& 14 & 447 & 1197 \\
& 21 & 299 & 873 \\
\hline
\end{tabular}

(d7). These comparisons represent two scenarios that assess differential gene expression in response to (1) seasonal changes in $\mathrm{pH}$ that occur in the present-day ( $\mathrm{pH} 8.13$ vs. 8.01), and (2) future ocean $\mathrm{pH}$ conditions (pH 7.71 vs. 8.01). The first comparison of $\mathrm{pH} 8.13$ vs. 8.01 represents gene expression patterns that might occur in response to ecologically relevant conditions, but on an acute time scale, i.e., on the order of days and not on the actual months-long time scale of the realtime transition of austral winter to austral summer. This sampling regime was necessitated by the reality of working in the field in Antarctica where the time to conduct experiments is limited.

Acute exposure to seasonally relevant changes in $\mathrm{pH}$ induced measurable changes in gene expression levels with a total of 263 transcripts changing in directional expression. Specifically, 168 transcripts were up-regulated, and 95 transcripts down-regulated in the high-pH (8.13) treatment when compared to the mid-pH (8.01) treatment (Table 2). The up-regulated transcripts were involved in methyltransferase activity, DNA Binding, ATPase activity, oxidoreductase activity, ion binding, and transmembrane transporter activity (Additional file 2). Further examination of this differential gene expression pattern found that within the up-regulated group there was enrichment of 5 gene ontologies associated with cytoskeleton function, calcium ion binding and microtubule based movement (Additional file 4, FDR <0.01). In contrast, the 95 downregulated transcripts were involved in DNA and poly(A) RNA binding, helicase activity, and the cytoskeleton structure; however, these transcripts had no associated enrichment patterns (Additional file 2).

By day 7, there was a significant increase in differential expression with approximately 8-times more genes changing in expression. Specifically, we identified 1554 transcripts up-regulated and 624 transcripts downregulated in the high-pH (8.13) treatment when compared to the mid-pH (8.01) treatment (Table 2). Among these up-regulated transcripts 31 sequences were involved in anatomical structure development, 123 were involved in cytoskeleton structure, and 70 were involved in ion binding (Additional file 2). Enrichment analyses of these differentially expressed transcripts identified 34 enriched gene ontologies that included calcium ion binding, actin binding, calmodulin binding, and the proteinaceous extracellular matrix (Additional file 4 , FDR < 0.01). Within the 624 down-regulated transcripts, 28 were involved in catalytic activity, 17 were involved in metabolic processes, and 29 of sequences were involved in cellular protein modification (Additional file 2). Once again, while there were a large number of differentially expressed transcripts that were down-regulated, there were no enrichment patterns associated with these transcripts.

The second comparison at $\mathrm{d} 1$ where future low $\mathrm{pH}$ conditions were examined ( $\mathrm{pH} 7.71$ vs. 8.01) identified a more pronounced change in the transcriptome. Here, 247 transcripts were up-regulated and 1818 transcripts were down-regulated in the low-pH (7.71) treatment when compared to the mid-pH (8.01) treatment (Table 2). Of the up-regulated transcripts, 15 were involved in ion binding, 14 were involved in catalytic activity, and 15 sequences were involved in catabolic processes (Additional file 3). However, a fisher's exact test of the 246 up-regulated transcripts produced no significant enrichments (FDR <0.05). Within the 1818 down-regulated transcripts, 152 transcripts were involved in catalytic activity (hydrolase and oxidoreductase activity), 62 sequences were involved in ion binding, and 101 sequences were involved in combined metabolic processes (Additional file 3). Enrichment analysis of the 1813 downregulated transcripts produced significant enrichments (FDR <0.01) in 20 ontological categories, including the proteinaceous extracellular matrix, transporter activity, catalase activity, chitin binding, and lipid transport (Additional file 5).

By $\mathrm{d} 7$, exposure to the low $\mathrm{pH}$ condition tapered to include 22 up-regulated transcripts, and 18 down regulated transcripts. Up-regulated transcripts were involved in transmembrane transport, the nuclear pore complex, and mRNA processing (Additional file 3). The set of downregulated transcripts contained transcripts that code for structural constituents of ribosomes, and developmental processes. Across both up- and down-regulated transcripts there was no gene ontology enrichment.

Changes in the transcriptome after 14 and 21 days In order to assess changes in the transcriptome after longterm acclimation to the $\mathrm{pH}$ treatments, we measured $\mathrm{DE}$ after 14 days (d14) and 21 days (d21) of incubation in treatment conditions. For these longer-term exposures, only the end-member $\mathrm{pH}$ treatments $(\mathrm{pH} 7.71$ vs. $\mathrm{pH}$ 8.13) were compared. This comparison spans the in situ $\mathrm{pH}$ range that pteropods are expected to experience annually by the year 2050 [9]. 
Following 14 days of exposure to $\mathrm{pH}$ 7.71, we observed a pronounced transcriptomic response where 377 transcripts were up-regulated, and 1197 transcripts were down-regulated (Table 2). Among the up-regulated transcripts, 32 transcripts were involved in cellular protein modification, 50 transcripts were involved in metabolic processes, and 36 transcripts were involved in macromolecule biosynthesis (Additional file 3). Enrichment analysis yielded no enriched gene ontologies for the upregulated transcript set. Among the 1197 downregulated transcripts a total of 94 transcripts were associated with metabolic processes, 105 with ion binding, and 124 with catalytic activity (Additional file 3). Further defining these terms found 75 transcripts were associated with calcium ion binding, 49 transcripts were associated with the cytoskeleton, and 21 transcripts were associated with ubiquitination. Enrichment analysis of the down-regulated transcripts identified 26 gene ontologies including single organism cellular process, ATP binding, calcium ion binding, protein kinase activity, and ion transmembrane transport (Additional file 5, FDR $<0.01$ ).

After 21 days of exposure to $\mathrm{pH} 7.71$, the response was somewhat attenuated with 241 up-regulated transcripts, and 872 down-regulated transcripts (Table 2). Among the up-regulated transcripts 24 transcripts were involved in translation, 17 transcripts were structural components of ribosomes, and 24 transcripts were involved in the formation of membrane-bound organelles (Additional file 3). In addition, 16 transcripts were found to be involved with catalytic activity, 20 with metabolic processes, and 6 with ion binding. Enrichment analysis of these up-regulated transcripts identified 7 enriched gene ontological terms (Additional file 5, FDR <0.05), all associated with membrane biogenesis and assembly. Among the down-regulated transcripts, 77 transcripts were associated with catalytic processes, 57 with metabolic processes, and 59 with ion binding (Additional file 3). A further definition of these terms found 40 transcripts associated with calcium ion binding, and 16 transcripts associated with the cytoskeleton. Enrichment analysis identified enrichment in 9 gene ontologies associated with ATP binding, ATPase activity, microtubule motor activity, and transport (i.e. ATP-binding cassette sub-family A) (Additional file 5, FDR $<0.01$ ).

\section{Physiologically relevant gene expression analysis}

In order to better characterize the response of the pteropods to $p \mathrm{CO}_{2}$ exposure, physiologically relevant gene sets were identified with Blastx searches of the $L . h$. antarctica transcriptome against the C. gigas genome [35] and the pteropod Heliconoides inflatus transcriptome [37]. These genes were used to identify differential expression patterns for four major physiological processes: shell formation, metabolism, the cellular stress response (CSR), and neural signaling. For each process we analyzed expression profiles for the acute $\left(\mathrm{T}_{0}, \mathrm{~d} 1\right.$, and $\left.\mathrm{d} 7\right)$, and acclimatory (d14 and d21) time points. The analysis of differentially expressed genes using the Fisher's exact test revealed enrichment only within the metabolic physiological process. Gene names from this analysis are listed in Additional files 6, 7, 8 and 9.

Shell formation response The Blastx search of the $L . h$. antarctica transcriptome against genes related to shell formation in the Pacific oyster [35] identified 1497 shell formation transcripts. Expression z-scores were calculated from FPKM values and filtered to include only these transcripts (Additional file 6). Expression profiles were analyzed at both the acute and acclimatory time points (Fig. 2ab).

The acute response within this subset of transcripts showed a clear clustering of the high-pH treatment ( $\mathrm{pH}$ 8.13) with $\mathrm{T}_{0}$ for both $\mathrm{d} 1$ and $\mathrm{d} 7$ (Fig. 2a). This cluster identified 1015 up-regulated, and 482 downregulated shell formation transcripts. The mid- and low$\mathrm{pH}$ treatments (8.01 and 7.71, respectively) cluster in a separate group with $\mathrm{d} 7$ showing the highest levels of similarity with 574 up-regulated, and 923 downregulated shell formation transcripts (Additional file 6).

This pattern was accentuated in the acclimatory response (d14 and d21) where higher expression levels of shell formation genes were detected in the high-pH treatment than in either the mid- or low-pH treatments (Fig. 2b). In addition, at these time points, treatments clustered together, showing a treatment-specific response. Specifically within the high-pH treatment, we identified 805 up-regulated, and 692 down-regulated shell formation transcripts. Within the mid-pH treatment these tapered to 530 up-regulated, and 967 down-regulated transcripts. This decline in expression continued in the low-pH treatment where only 282 transcripts were up-regulated and 1215 were down-regulated (Additional file 6).

Cellular stress response The Blastx search of the $L . h$. antarctica transcriptome against known stress-related genes from the Pacific oyster [35] identified 695 CSR transcripts. Expression FPKM values were filtered and $\mathrm{z}$ scores calculated for these 695 CSR transcripts (Additional file 7). Expression profiles were then analyzed at both the acute and acclimatory time points (Fig. 3a, b).

The acute response within this subset of transcripts revealed expression patterns that grouped $\mathrm{T}_{0}, \mathrm{~d} 1$ of the high-pH (8.13) exposure, and $\mathrm{d} 7$ of the mid-pH (8.01) treatments (Fig. 3a). Differential expression analysis for the CSR transcripts at these stages revealed $T_{0}$ to have 481 up-regulated transcripts and 214 down-regulated 

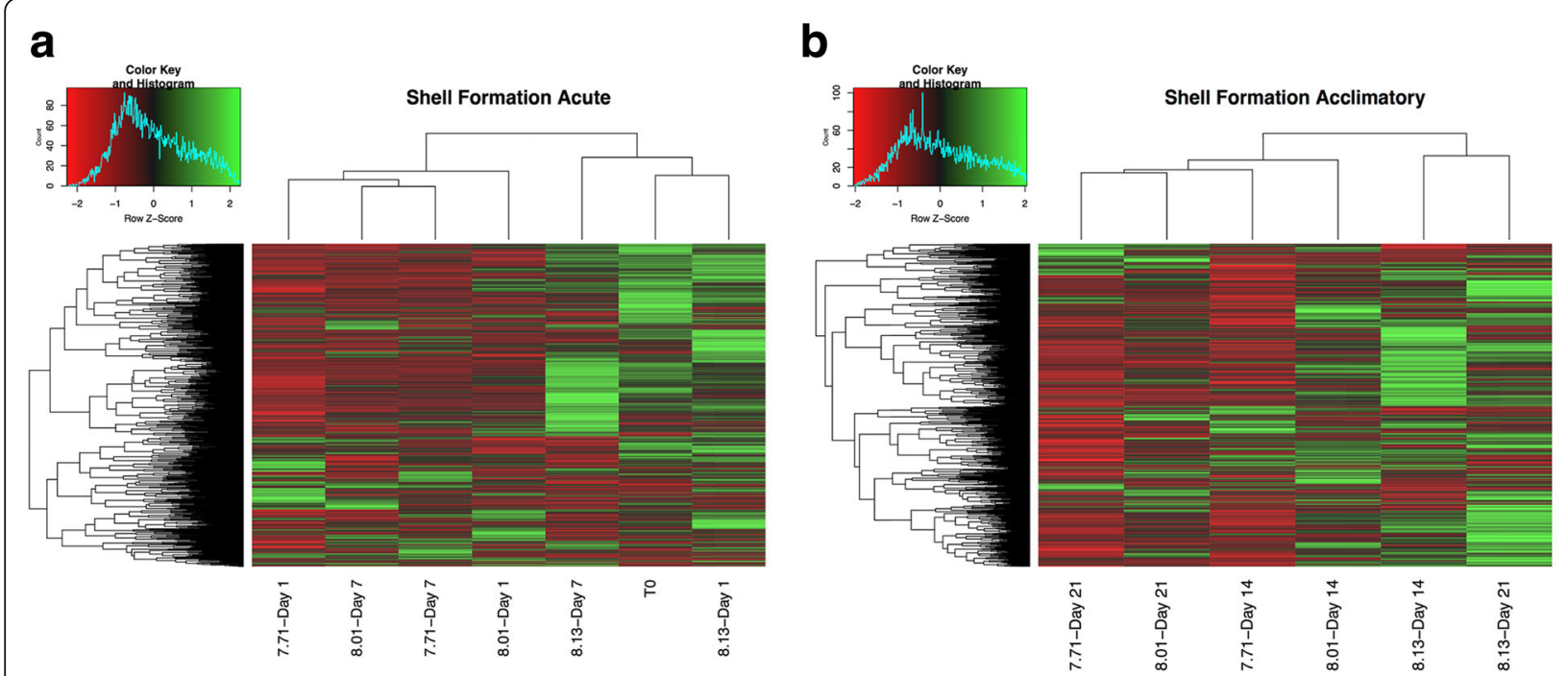

Fig. 2 Shell formation genes expression profiles. Heatmap of genes associated with shell formation. a clustering and heatmap of Z-scores for $T_{0}$ and the acute response ( $\mathrm{d} 1$ and $\mathrm{d} 7$ ) to all 3 treatment conditions (b) clustering and heatmap of Z-scores for the acclimatory response (d14 and d21). For both $\mathbf{a}$ and $\mathbf{b}$ are identified as treatment $(\mathrm{pH} 8.13, \mathrm{pH} 8.01, \mathrm{pH} 7.7)$ and Day $(1,7,14,21)$

transcripts and the high-pH treatment ( $\mathrm{d} 1$ and $\mathrm{d} 7)$ to have an average of 466 up-regulated and 229 downregulated transcripts. This clearly contrasts with the mid- and low-pH treatments that had on average of 272 up-regulated and 423 down-regulated CSR transcripts (Additional file 7).

The acclimatory response displayed a different trend wherein the mid-pH treatment clustered with the high$\mathrm{pH}$ treatments on $\mathrm{d} 14$, but clustered with the low-pH treatment on d21 (Fig. 3b). Assessing expression levels for these patterns revealed that the high-pH treatment on average (d14 and d21) expressed 371 up-regulated, and 324 down-regulated transcripts, the mid-pH treatment on average expressed 259 up-regulated, and 436 down-regulated transcripts, and the low-pH treatment on average expressed 130 up-regulated and 565 downregulated CSR transcripts (Additional file 7).

Metabolic response The Blastx search of the $L . h$. antarctica transcriptome against known metabolic genes a

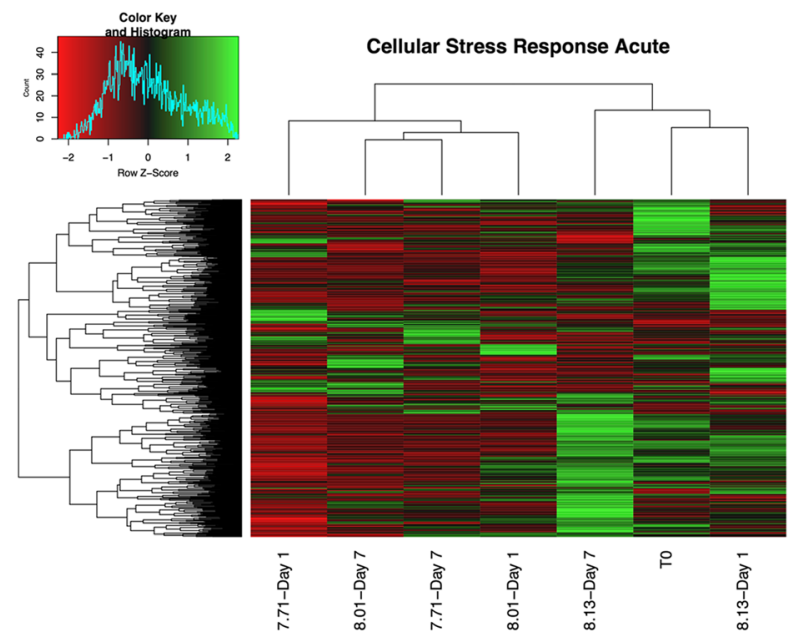

b
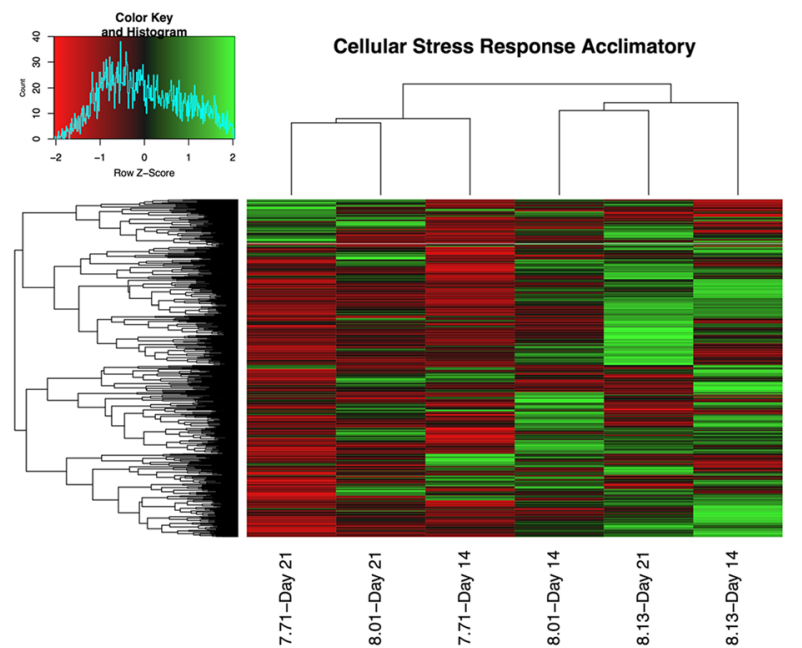

Fig. 3 Cellular stress response genes expression profiles. Heatmap of genes associated with the cellular stress response. a clustering and heatmap of Z-scores for $T_{0}$ and the acute response ( 11 and $d 7$ ) to all 3 treatment conditions. $\mathbf{b}$ clustering and heatmap of Z-scores for the acclimatory response (d14 and d21) 
from the Pacific oyster [35] identified 2139 metabolic transcripts. Expression FPKM values were filtered to include these metabolic transcripts, and z-score and expression profiles were again analyzed at both the acute and acclimatory time points (Fig. 4a,b, Additional file 8).

Clustering of the metabolic transcripts at the acute time points once again grouped $\mathrm{T}_{0}$ with the high-pH treatments ( $\mathrm{d} 1$ and $\mathrm{d} 7$ ) (Fig. 4a). In addition, the mid$\mathrm{pH}$ and low-pH treatments were very closely associated $\mathrm{w}$ the mid-pH d1 clustered with $\mathrm{d} 7$ of the low-pH treatment and $\mathrm{d} 7$ of the mid-pH treatment clustered with $\mathrm{d} 1$ of the low-pH treatment. The metabolic genes at this acute exposure once again are the most highly expressed in the high-pH treatment with an average of 1362 transcripts up-regulated for both $\mathrm{d} 1$ and $\mathrm{d} 7$. In contrast, the mid- and low-pH treatments had an average of 816 upregulated metabolic transcripts between $\mathrm{d} 1$ and $\mathrm{d} 7$ (Additional file 8).

The acclimatory response of this subset of metabolic transcripts revealed both a treatment-specific response, where the high-pH maintained the highest expression level of transcripts, and a temporal response where the mid- and low-pH treatments clustered together by day 21 (Fig. 4b). Evaluating the transcripts associated with each treatment revealed that the high-pH treatment once again had the highest level of expression with an average (d14 and d21) of 1082 up-regulated metabolic transcripts, the mid-pH treatment had 737 up-regulated metabolic transcripts, and the low-pH treatment only had 476 upregulated metabolic transcripts (Additional file 8).

To further assess the metabolism-associate gene expression a Fisher's exact test for each treatment revealed over-expression of genes for both the mid-pH and high-
$\mathrm{pH}$ treatments. Enrichment within the up-regulated transcripts in the mid-pH treatment identified overexpression of genes that are associated with calcium ion binding. In addition, this analysis identified an underexpression of genes associated with oxidoreductase activity. Enrichment analysis within the up-regulated transcripts in the high-pH treatment identified enrichment of 3 gene categories: nucleolus, rRNA metabolism, and histone modification. Finally, analysis of the downregulated transcripts in the high-pH treatment identified enrichment of calcium ion binding, transmembrane signaling receptor activity, and sulfuric ester hydrolase activity. In addition, there were 10 gene categories under-represented among the down-regulated transcripts, these include genes involved in RNA metabolic processes, translation, and intracellular membranebound organelle cellular components (Additional file 9).

Neural response The Blastx search of the $L$. $h$. antarctica transcriptome against previously identified neural genes differentially expressed in the pteropod Heliconoides inflatus [37] identified 191 neural transcripts. Expression FPKM values were filtered and z-scores calculated for these 135 neural transcripts (Additional file 9). Expression profiles for neural transcripts revealed large patterns associated with both acute and acclimatory responses to the $\mathrm{pH}$ treatments (Fig. 5a,b).

Clustering of the neural transcripts at the acute time points once again revealed clustering of high expression levels in both $\mathrm{T}_{0}$ and the high-pH treatments (d1 and d7) while the mid- and low-pH treatments exhibited dampened expression levels (Fig. 5a). Specifically, the high-pH treatment had an average of 79 up-regulated
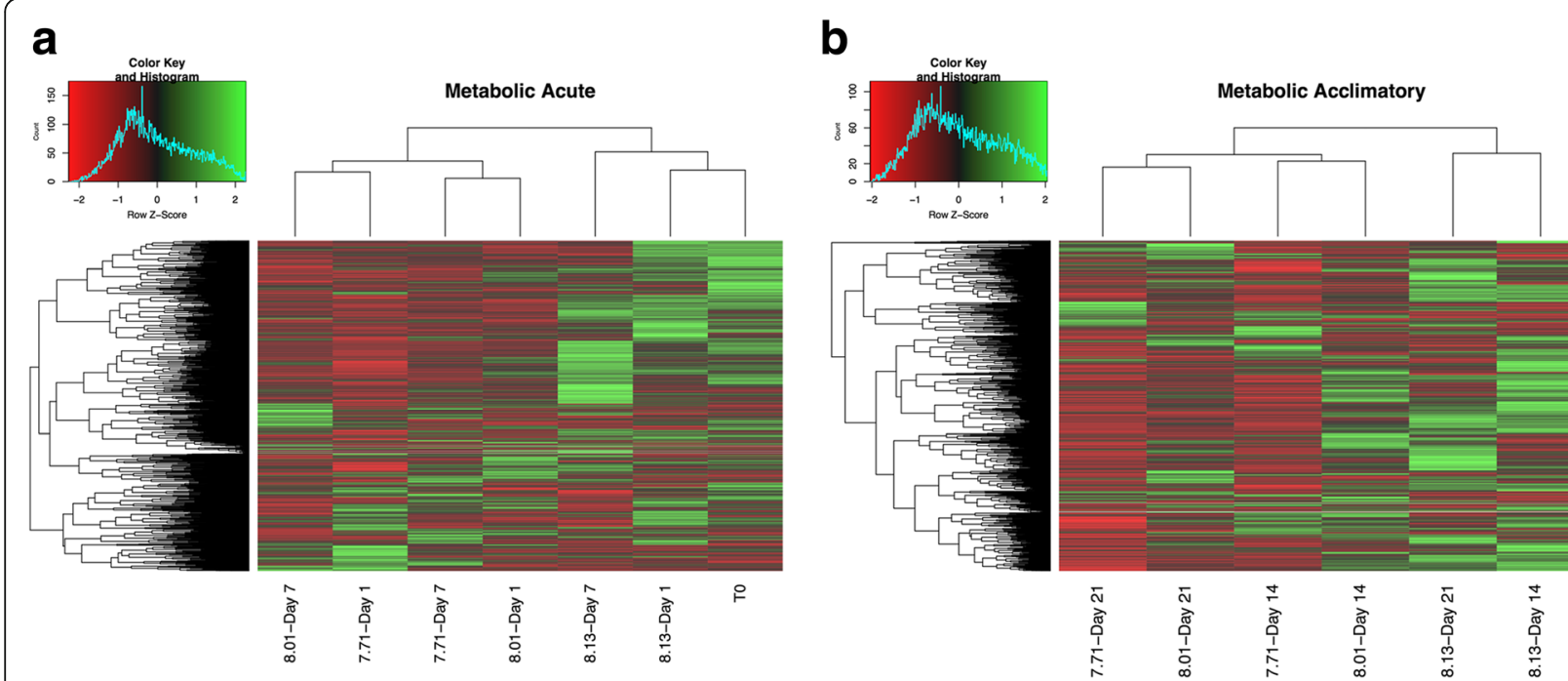

Fig. 4 Metabolic genes expression profiles. Heatmap of genes associated with metabolism. a clustering and heatmap of Z-scores for $T_{0}$ and the acute response ( $\mathrm{d} 1$ and $\mathrm{d} 7$ ) to all 3 treatment conditions. b clustering and heatmap of Z-scores for the acclimatory response (d14 and d21) 

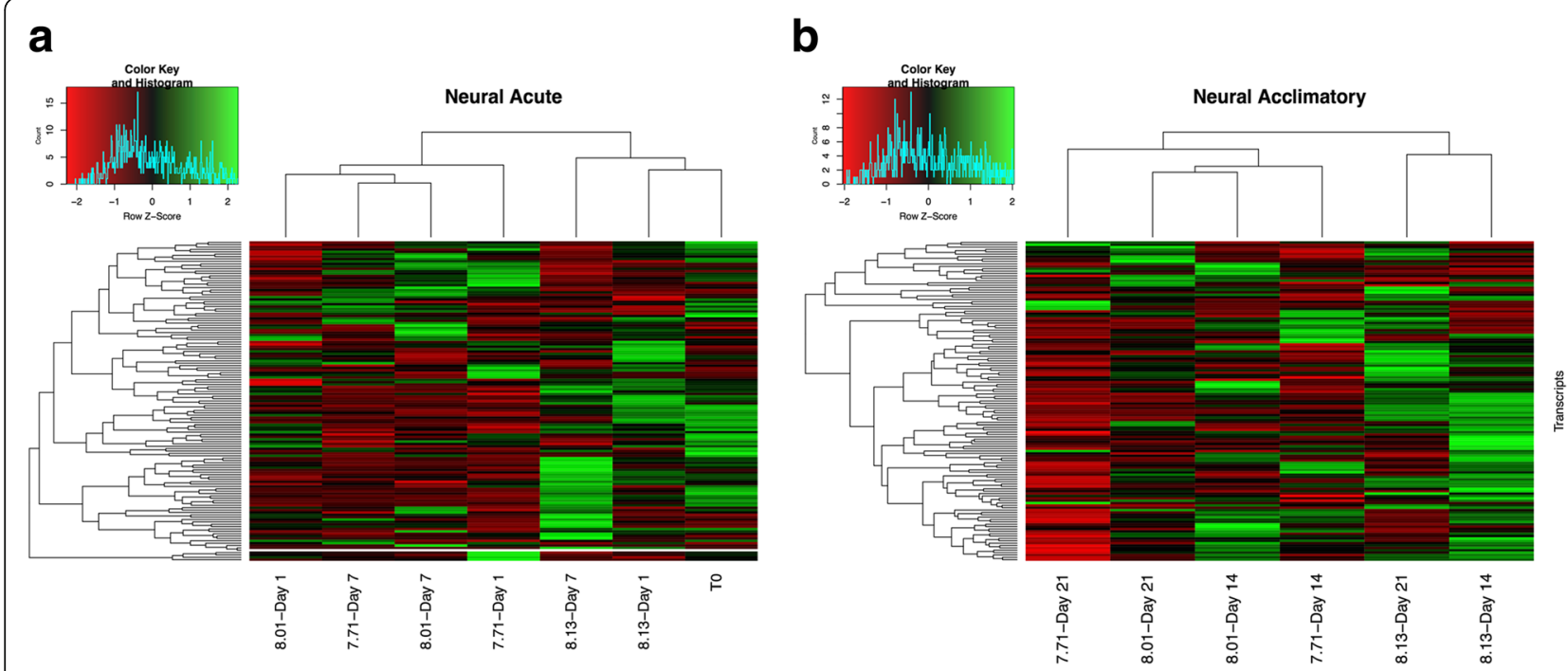

Fig. 5 Neural genes expression profiles. Heatmap of genes associated with neural function. a clustering and heatmap of Z-scores for $T_{0}$ and the acute response ( $\mathrm{d} 1$ and $\mathrm{d} 7$ ) to all 3 treatment conditions. $\mathbf{b}$ clustering and heatmap of Z-scores for the acclimatory response (d14 and d21)

neural transcripts while the mid- and low-pH treatments had 61 and 55 up-regulated neural transcripts, respectively (Additional file 9).

This trend of higher expression levels for genes related to neural processes in the high-pH treatment was maintained in the acclimatory time points (Fig. 5b). At these time points, we observed an average of 68 up-regulated transcripts in the high-pH treatment, 47 up-regulated transcripts in the mid-pH treatment, and an average of 33 up-regulated transcripts in the low-pH treatment. Expression levels continued to decline in the low-pH treatment such that by day 21 , only 23 neural transcripts were observed to be up-regulated (Additional file 9).

\section{Discussion}

Changes in the transcriptome can serve as a metric of physiological plasticity in metazoans in response to changes in their abiotic environment $[1,4,6,7,38]$. The goal of this study was to assess patterns of differential gene expression in the polar pteropod, Limacina helicina antarctica, in response to $\mathrm{pH}$ conditions that reflect both present-day, seasonal variability in $\mathrm{pH}$, and $\mathrm{pH}$ conditions predicted for future ocean acidification. In general, we found that the $L . h$. antarctica transcriptome changed in response to $\mathrm{pH}$ treatments that represented $\mathrm{pH}$ values for both seasonal, and ocean acidification conditions. In addition, the $L$. h. antarctica transcriptome changed as a function of time of exposure to the various $\mathrm{pH}$ treatments used in the experiment. Lastly, the expression patterns observed involved genes found in key processes that would be physiologically significant to a calcifying marine mollusk under these abiotic conditions in that these conditions may challenge biogenic calcification and energy allocation in a juvenile marine calcifier. Specifically, these four groups of genes are those involved in shell formation, the cellular stress response, metabolism, and neural function.

\section{Differential gene expression analysis Acute transcriptomic responses}

We found that $L$. $h$. antarctica had a robust transcriptional response to acute $\mathrm{pH}$ changes that represent present-day seasonal $\mathrm{pH}$ values (Tables 1 and 2). Specifically, in comparisons of expression for $\mathrm{pH} 8.13$ to 8.01 at day 1, strong up-regulation of transcripts involved with large-scale cellular function indicated a regulatory response to more alkaline conditions that typifies the transition from winter into summer [12]. Changes in transcript abundance of genes associated with DNA binding and epigenetic modifications such as DNA methylation (e.g. methyltransferases) indicated that the response may have involved epigenomic modifications that could act as mechanisms to change the transcriptome (Additional file 2).

Along with these genomic/epigenomic changes, we also observed increases in transcripts for calcium binding proteins (e.g. calmodulin-like proteins), ion binding, and transmembrane transporters, all genes known to be important in biogenic calcification (Additional file 2). In addition, functional enrichment analysis revealed enrichment of transcripts involved with cytoskeleton function and calcium ion binding (Additional file 4). The upregulation of these gene groups in the high-pH 
treatment suggests pteropods increased shell formation when held in conditions highly favorable for calcification.

Together, these results provide evidence that exposure to high $\mathrm{pH}$ conditions, which are presumably not physiologically stressful, led to broad scale transcriptomic changes that are focused on genome reorganization, and the maintenance and synthesis of cytoskeletal and calcified structures. Following 7 days of exposure these trends further intensified with 1554 upregulated transcripts that expanded the $\mathrm{d} 1$ regulated set to include anatomical structure development, and enrichment of cytoskeletal protein binding (Additional file 2). The continued increase in expression of genes associated with both the cytoskeleton and calcification indicated that pteropods up-regulate gene pathways associated with enhancing biogenic calcification when exposed to high-pH (8.13) conditions, the $\mathrm{pH}$ value observed during the peak of summer.

An examination of the suppressed transcripts for the acute seasonal $\mathrm{pH}$ treatment revealed minor downregulation in three gene types: nucleotide binding, helicase activity, and cytoskeleton structure (Additional file 2). While these results are similar to the transcripts identified in the up-regulated category, they represent a small number of isoforms that may have additional functions within these polar gastropods. Indeed, after 7 days of exposure, these contrasting transcripts were no longer present, and the residual suppressed transcripts were primarily involved in protein degradation (Additional file 2).

In general, differential gene expression analysis in juvenile $L$. $h$. antarctica revealed that acute exposure to $\mathrm{pH} 8.13$ produced dramatic transcriptional changes that were focused on cytoskeletal development and genome organization. While a robust transcriptional response is consistent with previous studies of the arctic form of $L$. h. helicina and the Mediterranean pteropod Heliconoides inflatus [22, 37], our results are the first to characterize the effects of $\mathrm{pH}$ on the Antarctic form of L. helicina. In addition, these data suggest that the juvenile pteropods were responding positively to seawater conditions that are typical of summer, a time when food supply is high and the growth potential is presumably also optimal for this polar species.

In contrast, exposure to $\mathrm{pH}$ conditions of ocean acidification ( $\mathrm{pH}$ 7.71) resulted in suppression of calcification, lipid transport, and metabolic function; suggesting that these conditions are physiologically stressful (Additional file 3). During the first $24 \mathrm{~h}$ of exposure, the dominant signature was a large-scale down-regulation of transcripts with enrichment in 20 gene ontologies (Additional file 5). Among these gene ontologies, three are noteworthy with regard to this suppression of gene expression in Limacina: (1) calcium ion binding, (2) chitin binding, and (3) the proteinaceous extra-cellular matrix. Within these down-regulated ontological groups are transcripts that code for tyrosinase, multiple chitinbinding proteins, calmodulin, carbonic anhydrase, Von Willebrand factor type A, Sushi, and bone morphogenic protein 1-like (Additional file 3). These genes are all known to have fundamental roles in the formation of the calcium carbonate shell of mollusks [39-43]. The suppression of these transcripts after $24 \mathrm{~h}$ of exposure to low $\mathrm{pH}$ conditions indicates that $\mathrm{pH}$-stressed pteropods rapidly suppress biogenic calcification.

In addition to changes in genes related to calcification, we also found significant impacts on genes associated with lipid transport, suggesting a shift in energetic needs in response to conditions of ocean acidification (Additional file 3) [44]. The downregulation of lipid transport genes points to a global disruption of energy allocation that corroborates other observations in studies on marine invertebrates including oysters, Antarctic krill and corals [45-47]. Changes in energy allocation for $L$. $h$. antarctica have been previously reported, wherein energy reserves in eggs were decreased when adults were exposed to low-pH conditions [48]. Similar effects of $\mathrm{pH}$ have also been reported in green sea urchins [49] and copepods, where low $\mathrm{pH}$ resulted in significant impacts on energy allocation and egg production [50].

That exposure to low-pH conditions impacted the energy budget of $L$. $h$. antarctica was further underscored by the down-regulation of metabolically important transcripts such as carbonic anhydrase, glucose dehydrogenase and malate dehydrogenase (Additional file 3). These genes are central to ATP production in metabolic pathways, and the integrity of energy metabolism has been identified as a key indicator of tolerance to abiotic stress [44]. Specifically, downregulation of glucose and malate dehydrogenase indicates a reduced ability to produce NADPH, a critical cofactor involved in oxidation-reduction, glutathione generation, and lipid synthesis. Down-regulation of these genes in response to conditions of ocean acidification has been documented in corals, oysters, and the great spider crab $[45,51,52]$.

By day 7, differential expression between the mid-pH (8.01) and the low-pH (7.71) was reduced to a total of 40 differentially expressed transcripts (Table 2). The upregulated transcripts were concentrated around transcription-related processes while down-regulated transcripts were involved in developmental processes. With so few differentially expressed transcripts, no gene ontological enrichment was present. The shift from high numbers of differentially expressed genes to this muted response suggests the transcriptomic profiles for the 
mid- and low-pH treatments were converging, an observation further supported by gene expression analysis of genes involved in physiological and cellular processes.

\section{Differential expression following short-term acclimation exposure}

As was observed with the acute exposures of juvenile Limacina, longer-term acclimation (14 to 21 days) to low $\mathrm{pH}$ conditions resulted in significant changes in gene expression (Table 2). In general, gene expression varied from the short-term response in that we observed a higher percentage of down-regulated transcripts at both $\mathrm{d} 14$ and $\mathrm{d} 21$. Specifically, at d14 the largest signal was among down-regulated transcripts with enrichment in 26 gene ontologies, an indication of large-scale reduction in transcription (Additional file 6). This was further supported by down-regulation of metabolic and ion binding transcripts, and indicated significant suppression of genes involved in biogenic calcification similar to the differential gene expression patterns observed in the acute response (Additional file 3). This pattern continued into d21 with down-regulation of cytoskeleton and calcium ion binding transcripts. Enrichment at d21 identified 9 enriched gene ontologies that reflect patterns identified during the acute exposure to low $\mathrm{pH}$ conditions (Additional file 6). With 872 down-regulated transcripts that continued to span calcium ion binding, metabolic function and cytoskeleton development, this pattern of differential expression is evidence that present-day pteropods genotypes do not modulate expression of candidate calcification genes that may be critical to continued calcification during the undersaturated austral winter conditions forecast for the Southern Ocean.

\section{Analysis of differential gene expression in physiologically relevant processes}

In order to better characterize the effect of $\mathrm{pH}$ on $L$. $h$. antarctica, we focused on 4 major processes that are key to pteropod physiology: shell formation, metabolism, the cellular stress response, and neural function. Overall, the differential gene expression analysis found that all 4 of these groups were predominately down-regulated when pteropods were exposed to low $\mathrm{pH}$ conditions. Below we briefly discuss each set of transcripts in these 4 categories.

\section{Shell formation response}

Expression patterns for genes involved in shell formation at the acute time points ( $\mathrm{d} 1$ and $\mathrm{d} 7)$ revealed a pattern of increased expression under the high-pH condition of 8.13, and very close clustering of expression profiles for both the mid-pH and low-pH conditions (Fig. 2a,b). At the acclimatory time points ( $\mathrm{d} 14$ and $\mathrm{d} 21)$, expression patterns for the three treatments partitioned into 3 categories that were associated with treatment conditions: high expression ( $\mathrm{pH}$ 8.13), mid expression ( $\mathrm{pH}$ 8.01), and low expression (pH 7.71) (Fig. 2b). These results support our position that long-term exposure to under-saturated conditions, mimicking those that $L$. $h$. antarctica are predicated to experience in winter by the year 2050, could limit the ability for pteropods to maintain calcified structures, and highlights the necessity for further functional validation of these effects.

Previous gene expression analysis for calcifying marine invertebrates has focused on a subset of shell formation genes that are impacted by changes in $\mathrm{pH}$ including calmodulin-like protein, chitin synthases, Ctype lectines, perlucin, and collagen associated transcripts [2, 22, 37, 53]. Within this subset of shell formation related transcripts, there was a clear downregulation associated with exposure to the low $\mathrm{pH}$ treatment (Additional file 6). Among these, calmodulin-like transcripts have been identified as important for calcification in the pearl oyster [42], and have been shown to be down-regulated in response to low $\mathrm{pH}$ in both oysters and corals $[41,53]$. Chitin synthase is also critical in coordinating shell formation for mollusks [54], and has also been reported to be down-regulated in Limacina spp. [22]. Finally, collagen-related transcripts (including C-type lectine, perlucin, and collagen-associated transcripts) have been shown to be important in shell formation in the disk abalone (Haliotis discus discus), and have been reported to be highly abundant in the mantle tissue of the Mediterranean mussel (Myilus galloprovincialis) $[55,56]$.

The heatmap displaying the broad patterns of gene expression in these shell formation genes (Fig. 2a, b) highlighted a subset of genes that were activated in response to low $\mathrm{pH}$. Among these up-regulated transcripts were tyrosinase tyr-3, chromatin assembly factor 1 subunit B-like, ribosome biogenesis homolog, ribosome-releasing factor mitochondrial-like, and a RNA-directed DNA polymerase from mobile element jockey-like gene (Additional file 6). Among these, tyrosinase tyr-3 has previously been shown to be up-regulated in the biomineralization process in the blue mussel (Mytlius edulis), and is associated with formation of new periostracum $[57,58]$.

\section{Metabolic response}

Expression patterns assessed in the metabolic response category revealed both temporal and pH-related patterns (Fig. 3a,b). Among these metabolic transcripts the highest levels of expression observed were in the $\mathrm{T}_{0}$ samples, and in the high $\mathrm{pH}$ treatments (Fig. 3a,b). The maintenance of $\mathrm{T}_{0}$ levels of expression for the first week of exposure, and continued grouping of the high $\mathrm{pH}$ treatments, suggests that food limitation was not a major obstacle for pteropods held in the $\mathrm{pH} 8.13$ treatment. 
The mid and low-pH treatments however showed significant depression of metabolism-associated transcripts that grouped the low and mid $\mathrm{pH}$ treatments with time of exposure. This suppression of metabolic genes in response to low $\mathrm{pH}$ has been documented in corals, urchins, and the Mediterranean pteropod Heliconoides inflautus [2, 37, 59, 60]. The enrichment of genes in both the mid-pH and high-pH treatments along with a dramatic reduction in metabolic transcript expression suggests energy demands under short-term exposure to low $\mathrm{pH}$ conditions were not met by an increase in metabolism. This result may reflect the limited feeding opportunities experienced in our flow-through Z-system; however, in situ, little is known about food availability throughout the light-limited austral winter.

\section{Cellular stress response}

Differential expression patterns for genes involved in the CSR provided additional evidence of a compromised transcriptional response in $L$. $h$. antarctica in response to low $\mathrm{pH}$. Up-regulated CSR transcripts associated with exposure to the low $\mathrm{pH}$ treatment were: HSP 70, heat-shock factor 2 binding protein-like gene, hydroxysteroid dehydrogenase 2-like gene, and a short-chain dehydrogenase/reductase family member 11-like gene (Additional file 6). In contrast, the transcripts down-regulated in the low $\mathrm{pH}$ conditions included those coding for multiple components of the cytochrome 450 pathway, the universal stress A-like protein, HSP 90-beta, and a glutathione mitochondrial-like protein.

The differential expression of key chaperones such as HSP 70 and HSP 90, genes critical for maintaining protein structure/function during oxidative stress, indicates that $\mathrm{pH}$ exposure in polar waters does not illicit a classic cellular stress response. Rather, exposure to low-pH conditions led to slight differential expression of these constitutively expressed genes. Within Antarctic species, high-levels of constitutive expression of CSR genes has been observed in Antarctic ectotherms, a response that is hypothesized to be due to increased levels of oxidative damage [61] and protein damage [62] caused by life at subzero temperatures. In this study, the differential expression of genes within the CSR indicated a mixed physiological response of L. h. antarctica to low $\mathrm{pH}$ conditions.

\section{Neural response}

In our project on Limacina, we specifically explored differential expression patterns in genes involved in neural function because previous work with $H$. inflatus correlated $\mathrm{pH}$ exposure to elevated expression of neural genes [37]. In our experiments however, exposure to low $\mathrm{pH}$ resulted in the opposite trend - namely, a decrease in expression levels of neural transcripts with the highest percentage found in the low $\mathrm{pH}$ treatment on $\mathrm{d} 21$ (Fig. 4b).
Acute exposure times clearly still grouped the high $\mathrm{pH}$ treatment with the $\mathrm{T}_{0}$ samples while both the mid and the low $\mathrm{pH}$ treatment exhibit a decrease in expression levels (Fig. 4a). Within the up-regulated neural gene set on $\mathrm{d} 21$, we found 5 neuronal acetylcholine receptors, and 4 NXPE type-2 transcripts (Additional file 9). These up-regulated transcripts correspond to similar upregulation of acetylcholine and neural transcripts observed in $H$. inflatus. The down-regulated transcripts included an acetylcholine receptor subunit delta-like, 4 transcripts for small conductance calcium-activated potassium channels and 5 skeletal receptor tyrosine kinase-like transcripts (Additional file 9). The proportion of down-regulated neural transcripts represent a morepronounced suppression of neural transcripts than was found in the $H$. inflatus transcriptome, potentially due to the shorter exposure time (3 days) and narrower gap in treatment conditions ( $\mathrm{pH} 7.9$ vs. $\mathrm{pH}$ 8.01). The upregulation of neuronal receptors coupled with the downregulation of potassium channels and skeletal tyrosine kinases suggest that exposure to the low-pH treatments will negatively affect locomotion. Here, prolonged exposures to low $\mathrm{pH}$ conditions might impact the ability for $L$. h. antarctica to maintain normal neuronal function that could, for example, impede feeding mechanisms and vertical migration under seawater conditions expected in the winter by the year 2050 .

\section{Other studies of comparative transcriptomic and ocean acidification}

Other investigators have assessed the impact of $p \mathrm{CO}_{2}$ levels on the transcriptome of marine invertebrates. These organisms include corals [2], oysters [51], sea urchins $[7,60,63]$, mussels $[56,64]$, and pteropods [22, 23, 37]. In general, our results are in alignment with these other studies, with the general result that changes in $p \mathrm{CO}_{2}$ exposure does alter the transcriptome. In addition, our results on the Antarctic form of Limacina helicina are largely consistent with what has been reported in pteropods as a taxonomic group. Specifically, working with the Arctic form of Limacina helicina, Koh and colleagues found significant down-regulation of biomineralization genes [22]. These results on polar Limacina spp. contrasts with what has been reported in a distantly related Mediterranean pteropod $H$. inflatus where low $\mathrm{pH}$ exposure elicited an up-regulation of biomineralization-related genes [37]. Within the Limacina complex this observed divergence in response suggests pteropods from the Southern Ocean may be more sensitive then the temperate pteropod $H$. infaltus to undersaturation conditions of ocean acidification, and did not maintain expression of calcification-related genes when exposed to low $\mathrm{pH}$ conditions. Lastly, although 
the effects of $\mathrm{pH}$ on calcification in Limacina spp. have been well documented [13, 16, 20, 21, 65-67], there remains an ongoing debate regarding the ability for Limacina spp. to utilize internal shell repair mechanisms to minimize the deleterious impacts of ocean acidification $[65,68,69]$. However, this study along with the transcriptome study presented by Koh et al. [22] suggests that all forms of Limacina helicina are challenged to maintain calcification in low $\mathrm{pH}$ conditions.

\section{Conclusion}

In the present study, we have reported significant changes in the transcriptome of juvenile Limacina helicina antarctica in response to $p \mathrm{CO}_{2}$ conditions in the laboratory that mimics present-day and future conditions. The shellforming pteropod, $L$. $h$. antarctica, exhibited sensitivity to low $\mathrm{pH}$ stress with significant down-regulation of genes involved in shell formation, metabolism, and the cellular stress response. These results from experiments suggest that contemporary Limacina did not increase the expression of genes involved in shell formation in order to compensate for the physiological stress induced by ocean acidification in situ. These results extend our understanding of how this key Antarctic zooplankton species will respond to prolonged exposure to low $\mathrm{pH}$ conditions predicted to occur by the winter of 2050. In addition, this study presents an ideal framework from which hypothesis-driven functional validation studies of these effected pathways can be developed.

\section{Additional files}

Additional file 1: Transcriptome assembly and annotation statistics. This file provides further assembly and annotation statistics for the de novo transcriptome. File includes: assembly statistics, gene ontology distribution, and KEGG enzyme mapping. (PDF $117 \mathrm{~kb}$ )

Additional file 2: Seasonal differential expression gene list. This file provides the list of all genes identified in the seasonal differential gene expression analysis. File contains, sequence identifier, sequence description, enzyme codes, gene ontology identifiers, gene ontology names, logFC (Fold Change), logCPM (Counts per million), $P$-values, and FDR (false discovery rate). (XLSX $322 \mathrm{~kb}$ )

Additional file 3: Ocean acidification differential expression gene list. This file provides the list of all genes identified in the ocean acidification differential gene expression analysis. File contains, sequence identifier, sequence description, enzyme codes, gene ontology identifiers, gene ontology names, logFC (Fold Change), logCPM (Counts per million), P-values, and FDR (false discovery rate). (XLSX $741 \mathrm{~kb}$ )

Additional file 4: Seasonal enriched gene ontologies. This file provides the list of all gene ontologies identified as enriched in the seasonal differential gene expression analysis using the Fisher's Exact Test. File contains: $\mathrm{pH}$ comparison, day, gene ontology ID, gene ontology name, FDR (false discovery rate), P-value, Gene ontology category, number of transcripts in test (i.e. those that were differentially expressed), and number of transcripts in the reference transcriptome. (XLSX $11 \mathrm{~kb}$ )

Additional file 5: Ocean acidification enriched gene ontologies. This file provides the list of all gene ontologies identified as enriched in the ocean acidification differential gene expression analysis using the Fisher's Exact Test. File contains: pH comparison, day, gene ontology ID, gene ontology name, FDR (false discovery rate), P-value, Gene ontology category, number of transcripts in test (i.e. those that were differentially expressed), and number of transcripts in the reference transcriptome. (XLSX 56 kb)

Additional file 6: Gene identifiers and calculated z-scores for shell formation analysis. This file provides the list and $z$-score of all genes identified in the shell formation analysis. File contains, sequence identifier, sequence description, enzyme codes, gene ontology identifiers, gene ontology names, gene ontology category, and z-scores for each sample. (XLSX 366 kb)

Additional file 7: Gene identifiers and calculated $z$-scores for the cellular stress response analysis. This file provides the list and $z$-score of all genes identified in the cellular stress response gene analysis. File contains, sequence identifier, sequence description, enzyme codes, gene ontology identifiers, gene ontology names, gene ontology category, and z-scores for each sample. (XLSX $176 \mathrm{~kb}$ )

Additional file 8: Gene identifiers and calculated z-scores for the metabolic gene analysis. This file provides the list and $z$-score of all genes identified in the metabolism analysis. File contains, sequence identifier, sequence description, enzyme codes, gene ontology identifiers, gene ontology names, gene ontology category, and z-scores for each sample. (XLSX $549 \mathrm{~kb})$

Additional file 9: Gene identifiers and calculated z-scores for the neural gene analysis. This file provides the list and z-score of all genes identified in the neural gene analysis. File contains, sequence identifier, sequence description, enzyme codes, gene ontology identifiers, gene ontology names, gene ontology category, and z-scores for each sample. (XLSX $39 \mathrm{~kb})$

\section{Abbreviations}

bp: Base pair; $\mathrm{CO}_{2}$ : Carbon dioxide; CSR: Cellular stress response; FPKM: Fragments per kilobase of transcript per million mapped reads; GO: Gene ontology; HSP: Heat shock proteins; KEGG: Kyoto Encyclopedia of Genes and Genomes; NCBI: NATIONAL Center for Biotechnology Information; $\mathrm{OA}$ : Ocean acidification; $\mathrm{PCO}_{2}$ : Partial pressure of carbon dioxide; RNASeq: RNA sequencing

\section{Acknowledgements}

The authors would like to thank members of the U.S. Antarctic Program, and Lockheed's Antarctic Support Corporation (ASC) for support at McMurdo Station, Antarctica during the 2015-2016 Winter and Summer Field Seasons.

\section{Funding}

This research was supported by a grant from the U.S. National Science Foundation (NSF) through the U.S. Antarctic Program (PLR-1246202) to GEH. During the course of this project, KMJ was supported by a U.S. NSF Graduate Research Fellowship under grant no. 1650114. Specimens were collected in compliance with U.S. regulations that govern collection of Antarctic organisms: the Antarctic Conservation Act of 1978 (Public Law 95-541), and the Antarctic Marine Living Resources Convention Act of 1984 (Public Law 98-623). The sequencing was carried out at the DNA Technologies and Expression Analysis Cores at the UC Davis Genome Center, supported by NIH Shared Instrumentation Grant 1S100D010786-01. We acknowledge support from the Center for Scientific Computing at the Center for Nano Systems Institute at UC Santa Barbara under NSF award CNS-0960316.

\section{Availability of data and materials}

The expression data used in this study is publicly available at the NCBI short read archive (SRA); accession SUB2660536. The Limacina helicina antarctica transcriptome can be found in the SRA database under BioProject PRJNA295792, with accession number SRR2463656. The annotated transcriptome can be located on the DDBJ/EMBL/GenBank transcriptome shotgun assembly (TSA) database under the accession GDRM00000000.

\section{Authors' contributions}

$\mathrm{GH}$ conceived of and designed the study; GH and $\mathrm{KJ}$ collected pteropods for the study; KJ isolated the RNA, prepared libraries and performed the bioinformatic analysis; $\mathrm{GH}$ and $\mathrm{KJ}$ analyzed the results and wrote the manuscript. All authors have read and approved the final version of this manuscript. 


\section{Ethics approval and consent to participate}

Not applicable

\section{Consent for publication \\ Not applicable.}

\section{Competing interests}

The authors declare that they have no competing interests.

\section{Publisher's Note}

Springer Nature remains neutral with regard to jurisdictional claims in published maps and institutional affiliations.

\section{Author details}

'Department of Ecology, Evolution and Marine Biology, University of California, Santa Barbara, Santa Barbara, CA 93106-9620, USA. ²Department of Biological Sciences, Louisiana State University, Baton Rouge, LA 70803-0001, USA.

Received: 15 May 2017 Accepted: 5 October 2017

Published online: 23 October 2017

\section{References}

1. DeBiasse MB, Kelly MW. Plastic and evolved responses to global change: what can we learn from comparative transcriptomics? J Hered. 2016;107(1): 71-81.

2. Moya A, Huisman L, Ball EE, Hayward DC, Grasso LC, Chua CM, Woo HN, Gattuso JP, Foret S, Miller DJ. Whole transcriptome analysis of the coral Acropora millepora reveals complex responses to $\mathrm{CO}_{2}$-driven acidification during the initiation of calcification. Mol Ecol. 2012;21(10):2440-54.

3. Smith $S$, Bernatchez $L$, Beheregaray LB. RNA-seq analysis reveals extensive transcriptional plasticity to temperature stress in a freshwater fish species. BMC Genomics. 2013;14(1):375.

4. Gleason LU, Burton RS. RNA-seq reveals regional differences in transcriptome response to heat stress in the marine snail Chlorostoma funebralis. Mol Ecol. 2015;24(3):610-27.

5. Wang W, Hui JHL, Williams GA, Cartwright SR, Tsang LM, Chu KH. Comparative transcriptomics across populations offers new insights into the evolution of thermal resistance in marine snails. Mar Biol. 2016;163(4):92.

6. Stillman JH, Armstrong E. Genomics are transforming our understanding of responses to climate change. Bioscience. 2015;65(3):237-46.

7. Evans TG, Pespeni MH, Hofmann GE, Palumbi SR, Sanford E. Transcriptomic responses to seawater acidification among sea urchin populations inhabiting a natural pH mosaic. Mol Ecol. 2017;26(8):2257-75.

8. McNeil Bl, Matear RJ. Southern Ocean acidification: a tipping point at 450ppm atmospheric $\mathrm{CO}_{2}$. Proc Natl Acad Sci. 2008;105(48):18860-4.

9. Hauri C, Friedrich T, Timmermann A. Abrupt onset and prolongation of aragonite undersaturation events in the Southern Ocean. Nat Clim Chang. 2016, 6;172-76. doi:10.1038/nclimate2844.

10. Fabry VJ, McClintock JB, Mathis JT, Grebmeier JM. Ocean acidification at high latitudes: the bellweather. Oceanography. 2009;22(4):160-71.

11. Orr JC. Recent and future changes in ocean carbonate chemistry. Ocean Acidification. ed J-P Gattuso and L Hansson. Oxford: Oxford University Press; 2011. p. 41-66.

12. Kapsenberg L, Kelley AL, Shaw EC, Martz TR, Hofmann GE. Near-shore Antarctic $\mathrm{pH}$ variability has implications for the design of ocean acidification experiments. Sci Rep. 2015;5:9638.

13. Bednaršek N, Tarling GA, Bakker DCE, Fielding S, Feely RA. Dissolution dominating calcification process in polar pteropods close to the point of aragonite undersaturation. PLoS One. 2014;9(10)

14. Johnson KM, Hoshijima U, Sugano CS, Nguyen AT, Hofmann GE. Shell dissolution observed in Limacina helicina antarctica from the Ross Sea, Antarctica: paired shell characteristics and in situ seawater chemistry. Biogeosci Discuss. 2016;2016:1-25.

15. Bernard KS, Steinberg DK, Schofield OME. Summertime grazing impact of the dominant macrozooplankton off the western Antarctic peninsula. Deep Sea Research Part I: Oceanographic Research. 2012;62:111-22.

16. Bednaršek N, Tarling GA, Bakker DCE, Fielding S, Jones EM, Venables HJ, Ward P, Kuzirian A, Leze B, Feely RA, et al. Extensive dissolution of live pteropods in the Southern Ocean. Nat Geosci. 2012;5(12):881-5.
17. Manno C, Sandrini S, Tositti L, Accornero A. First stages of degradation of Limacina helicina shells observed above the aragonite chemical lysocline in Terra Nova Bay (Antarctica). J Mar Syst. 2007;68(1-2):91-102.

18. Manno C, Bednaršek N, Tarling GA, Peck VL, Comeau S, Adhikari D, Bakker DCE, Bauerfeind E, Bergan AJ, Berning MI, et al. Shelled pteropods in peril: assessing vulnerability in a high $\mathrm{CO}_{2}$ ocean. Earth Sci Rev. 2017;169:132-145. doi:10.1016/j.earscirev.2017.04.005.

19. Fabry VJ, Seibel BA, Feely RA, Orr JC. Impacts of ocean acidification on marine fauna and ecosystem processes. ICES J Mar Sci. 2008;65(3):414-32.

20. Comeau S, Alliouane SGJ, Alliouan S, Gattuso JP. Effects of ocean acidification on overwintering juvenile Arctic pteropods Limacina helicina. Mar Ecol Prog Ser. 2012;456:6.

21. Lischka S, Büdenbender J, Boxhammer T, Leibniz-Riebesel U. Impact of ocean acidification and elevated temperatures on early juveniles of the polar shelled pteropod Limacina helicina: mortality, shell degradation, and shell growth. Biogeosciences. 2011;8(4):919-32.

22. Koh HY, Lee JH, Han SJ, Park H, Shin SC, Lee SG. A transcriptomic analysis of the response of the arctic pteropod Limacina helicina to carbon dioxide-driven seawater acidification. Polar Biol. 2015;38:1727-40.

23. Maas AE, Lawson GL, Tarrant AM. Transcriptome-wide analysis of the response of the thecosome pteropod Clio pyramidata to short-term $\mathrm{CO}_{2}$ exposure. Comp Biochem Physiol Part D Genomics Proteomics. 2015;16:1-9.

24. Fangue NA, O'Donnell MJ, Sewell MA, Matson PG, MacPherson AC, Hofmann GE. A laboratory-based, experimental system for the study of ocean acidification effects on marine invertebrate larvae. Limnology and Oceanography-Methods. 2010;8:441-52.

25. Foster BA. Composition and abundance of zooplankton under the spring sea-ice of McMurdo sound. Polar Biol. 1987;8(1):41-8.

26. Clayton TD, Byrne RH. Spectrophotometric seawater pH measurements: total hydrogen ion concentration scale calibration of m-cresol purple and at-sea results. Deep Sea Res. 1993;40(10):2115-29.

27. Dickson $A G$, Sabine $C L$, Christian JR. Guide to best practices for ocean $\mathrm{CO}_{2}$ measurements. PICES Special Publication. 2007:3:191.

28. Robbins LL, Hansen ME, Kleypas JA, Meylan SC. CO2calc - a user-friendly seawater carbon calculator for windows, $\max$ OS X, and iOS (iPhone). In: US geological survey open-file report 2010-1280; 2010.

29. Comparison of RIN and RINe algorithms for the Agilent 2100 Bioanalyzer and the Agilent 2200 TapeStation systems. Edited by @ Agilent Technologies I. http://www.agilent.com/cs/library/technicaloverviews/ public/5990-9613EN.pdf; 2012: 4. Accessed 1 Oct 2016.

30. Borodina T, Adjaye J, Sultan M. A strand-specific library preparation protocol for RNA sequencing. Methods Enzymol. 2011;500:79-98.

31. Johnson KM, Hofmann GE: A transcriptome resource for the Antarctic pteropod Limacina helicina antarctica. Mar Genomics 2016, 28:25-8.

32. Li B, Dewey CN. RSEM: accurate transcript quantification from RNA-Seq data with or without a reference genome. BMC Bioinformatics. 2011;12:323.

33. Zhou X, Lindsay H, Robinson MD. Robustly detecting differential expression in RNA sequencing data using observation weights. Nucleic Acids Res. 2014; 42(11):e91.

34. Khang TF, Lau CY. Getting the most out of RNA-seq data analysis. PeerJ. 2015;3:e1360.

35. Conesa A, Gotz S, Garcia-Gomez JM, Terol J, Talon M, Robles M. Blast2GO: a universal tool for annotation, visualization and analysis in functional genomics research. Bioinformatics (Oxford, England). 2005; 21(18):3674-6.

36. Zhang G, Fang X, Guo X, Li L, Luo R, Xu F, Yang P, Zhang L, Wang X, Qi H, et al. The oyster genome reveals stress adaptation and complexity of shell formation. Nature, 2012, 490;7418:49-54.

37. Moya A, Howes EL, Lacoue-Labarthe T, Foret S, Hanna B, Medina M, Munday PL, Ong JS, Teyssie JL, Torda G, et al. Near-future pH conditions severely impact calcification, metabolism and the nervous system in the pteropod Heliconoides inflatus. Glob Chang Biol. 2016;22(12):3888-900.

38. Evans TG. Considerations for the use of transcriptomics in identifying the 'genes that matter' for environmental adaptation. J Exp Biol. 2015;218(12):1925-35.

39. Zhao M, Shi Y, He M, Huang X, Wang Q. PfSMAD4 plays a role in biomineralization and can transduce bone morphogenetic protein-2 signals in the pearl oyster Pinctada fucata. BMC Dev Biol. 2016;16(1):9.

40. Liu C, Li S, Kong J, Liu Y, Wang T, Xie L, Zhang R. In-depth proteomic analysis of shell matrix proteins of Pinctada fucata. Sci Rep. 2015;5:17269. 
41. Liu W, Huang X, Lin J, He M. Seawater acidification and elevated temperature affect gene expression patterns of the pearl oyster Pinctada fucata. PLoS One. 2012;7(3):e33679.

42. Yan Z, Fang Z, Ma Z, Deng J, Li S, Xie L, Zhang R. Biomineralization: functions of calmodulin-like protein in the shell formation of pearl oyster. Biochim Biophys Acta. 2007;1770(9):1338-44.

43. Li S, Xie L, Zhang C, Zhang Y, Gu M, Zhang R. Cloning and expression of a pivotal calcium metabolism regulator: calmodulin involved in shell formation from pearl oyster (Pinctada fucata). Comp Biochem Physiol B Biochem Mol Biol. 2004;138(3):235-43.

44. Sokolova IM. Energy-limited tolerance to stress as a conceptual framework to integrate the effects of multiple stressors. Integr Comp Biol. 2013;53(4):597-608.

45. Zoccola D, Innocenti A, Bertucci A, Tambutté E, Supuran TC, Tambutté S. Coral carbonic anhydrases: regulation by ocean acidification. Mar Drugs. 2016:14(6):e109. doi:10.3390/md14060109.

46. Saba GK, Schofield O, Torres JJ, Ombres EH, Steinberg DK. Increased feeding and nutrient excretion of adult Antarctic krill, Euphausia superba exposed to enhanced carbon dioxide $\left(\mathrm{CO}_{2}\right)$. PLoS One. 2012;7(12):e52224.

47. Dickinson $\mathrm{GH}$, Ivanina AV, Matoo OB, Poertner HO, Lannig G, Bock C, Beniash E, Sokolova IM. Interactive effects of salinity and elevated $\mathrm{CO}_{2}$ levels on juvenile eastern oysters, Crassostrea virginica. J Exp Biol. 2012;215(1):29-43.

48. Manno C, Peck VL, Tarling GA. Pteropod eggs released at high $\mathrm{pCO}_{2}$ lack resilience to ocean acidification. Sci Rep. 2016;6:e25752. doi:10.1038/srep25752.

49. Dupont S, Dorey N, Stumpp M, Melzner F, Thorndyke M. Long-term and trans-life-cycle effects of exposure to ocean acidification in the green sea urchin Strongylocentrotus droebachiensis. Mar Biol. 2013;160(8):1835-43.

50. De Wit P, Dupont S, Thor P. Selection on oxidative phosphorylation and ribosomal structure as a multigenerational response to ocean acidification in the common copepod Pseudocalanus acuspes. Evol Appl. 2016;9(9):1112-23.

51. Li S, Huang J, Liu C, Liu Y, Zheng G, Xie L, Zhang R. Interactive effects of seawater acidification and elevated temperature on the transcriptome and biomineralization in the pearl oyster Pinctada fucata. Environ Sci Technol. 2016;50(3):1157-65.

52. Harms L, Frickenhaus S, Schiffer M, Mark FC, Storch D, Held C, Portner HO, Lucassen M. Gene expression profiling in gills of the great spider crab Hyas araneus in response to ocean acidification and warming. BMC Genomics. 2014;15:789.

53. Kaniewska P, Campbell PR, Kline DI, Rodriquez-Lanetty M, Miller DJ, Dove S, Hoegh-Guldberg O. Major cellular and physiological impacts of ocean acidification on a reef building coral. PLoS One. 2012;7(4):e34659.

54. Schönitzer $V$, Weiss IM. The structure of mollusc larval shells formed in the presence of the chitin synthase inhibitor Nikkomycin Z. BMC Struct Biol. 2007;7(1):71

55. Wang $\mathrm{N}$, Lee $\mathrm{YH}$, Lee J. Recombinant perlucin nucleates the growth of calcium carbonate crystals: molecular cloning and characterization of perlucin from disk abalone, Haliotis discus discus. Comp Biochem Physiol B Biochem Mol Biol. 2008;149(2):354-61.

56. Moreira R, Pereiro P, Canchaya C, Posada D, Figueras A, Novoa B. RNA-Seq in Mytilus galloprovincialis: comparative transcriptomics and expression profiles among different tissues. BMC Genomics. 2015;16(1):728.

57. Marin F, Luquet G, Marie B, Medakovic D. Molluscan shell proteins: primary structure, origin, and evolution. In: Current topics in developmental biology, vol. 80: Academic Press; 2007. p. 209-76. ISBN 9780123739148, https://doi. org/10.1016/S0070-2153(07)80006-8.

58. Hüning AK, Lange SM, Ramesh $K$, Jacob DE, Jackson DJ, Panknin U, Gutowska MA, Philipp EER, Rosenstiel P, Lucassen M, et al. A shell regeneration assay to identify biomineralization candidate genes in mytilid mussels. Mar Genomics. 2016;27:57-67.

59. Kroeker KJ, Kordas RL, Crim RN, Singh GG. Meta-analysis reveals negative yet variable effects of ocean acidification on marine organisms. Ecol Lett. 2010; 13(11):1419-34.

60. Todgham AE, Hofmann GE. Transcriptomic response of sea urchin larvae Strongylocentrotus purpuratus to $\mathrm{CO}_{2}$-driven seawater acidification. J Exp Biol. 2009:212(16):2579-94

61. Place SP, Zippay ML, Hofmann GE. Constitutive roles for inducible genes: evidence for the alteration in expression of the inducible hsp70 gene in Antarctic notothenioid fishes. Am J Physiol Regul Integr Comp Physiol. 2004;287(2):R429-36

62. Huth TJ, Place SP. Transcriptome wide analyses reveal a sustained cellular stress response in the gill tissue of Trematomus bernacchii after acclimation to multiple stressors. BMC Genomics. 2016;17:18.
63. Evans TG, Chan F, Menge BA, Hofmann GE. Transcriptomic responses to ocean acidification in larval sea urchins from a naturally variable $\mathrm{pH}$ environment. Mol Ecol. 2013;22(6):1609-25.

64. Kelly MW, Padilla-Gamiño JL, Hofmann GE. High $\mathrm{pCO}_{2}$ affects body size, but not gene expression in larvae of the California mussel (Mytilus californianus). ICES J Mar Sci. 2016;73(3):962-9.

65. Bednaršek N, Johnson J, Feely RA. Vulnerability of pteropod (Limacina helicina) to ocean acidification: shell dissolution occurs despite an intact organic layer. Deep-Sea Res II Top Stud Oceanogr. 2016;127:53-56. doi:10. 1016/j.dsr2.2016.03.006.

66. Bednaršek N, Tarling GA, Bakker DC, Fielding S, Cohen A, Kuzirian A, McCorkle D, Lézé B, Montagna R. Description and quantification of pteropod shell dissolution: a sensitive bioindicator of ocean acidification. Glob Chang Biol. 2012;18(7):2378-88.

67. Comeau S, Jeffree R, Teyssie JL, Gattuso JP. Response of the Arctic pteropod Limacina helicina to projected future environmental conditions. PLoS One. 2010;5(6):e11362.

68. Peck VL, Tarling GA, Manno C, Harper EM. Response to comment vulnerability of pteropod (Limacina helicina) to ocean acidification: Shell dissolution occurs despite an intact organic layer by Bednaršek et al. Deep-Sea Res Part II: Topical Studies in Oceanography. 2016;127:57-59. https://doi.org/10.1016/j.dsr2.2016.03.007.

69. Peck VL, Tarling GA, Manno C, Harper E, Tynan E. Outer organic layer and internal repair mechanism protects pteropod Limacina helicina from ocean acidification. Deep Sea Research Part II: Topical Studies in Oceanography. 2016:127:41-52. https://doi.org/10.1016/j.dsr2.2015.12.005.

\section{Submit your next manuscript to BioMed Central and we will help you at every step:}

- We accept pre-submission inquiries

- Our selector tool helps you to find the most relevant journal

- We provide round the clock customer support

- Convenient online submission

- Thorough peer review

- Inclusion in PubMed and all major indexing services

- Maximum visibility for your research

Submit your manuscript at www.biomedcentral.com/submit
) Biomed Central 